Heredity (1979), 42 (1), 13-32

\title{
THE STRUCTURE OF THE HYBRID ZONE IN CALEDIA CAPTIVA
}

\author{
C. MORAN \\ Department of Population Biology, Research School of Biological Sciences, Australian National \\ University, Canberra, A.C.T. 2601
}

Received 19.vi.78

\begin{abstract}
SUMmary
The " Moreton" and "Torresian" races of Caledia captiva are parapatrically distributed in south-east Queensland. Although no obvious morphological differences exist between these taxa, there is a very high level of karyotypic divergence. An analysis of the structure of the contact zone has revealed that the transition from one race to the other occurs very abruptly, with approximately 65 per cent of the change in racial frequencies occurring in a $200 \mathrm{~m}$ interval. The total width of the zone of hybridisation is $1 \mathrm{k}$ and within this area, mating occurs randomly within and between the races. Analyses of the karyotypic data have established that there is rapid elimination of "Moreton" autosomes on the "Torresian" side of the zone, but that "Torresian" autosomes are retained on the "Moreton" side. Further, the patterns of chromosomal gametic disequilibria differ on the two sides of the zone, providing evidence of asymmetrical hybrid breakdown and supporting the hypothesis of one-way introgression of autosomes from the "Torresian" into the "Moreton" race. A deterministic model examines the effect of hybrid breakdown in a contact zone.
\end{abstract}

\section{INTRODUGTION}

HYBRID zones, recognisable on morphological or chromosomal criteria have been found in many groups of invertebrates and vertebrates (Mayr, 1963; Short, 1972; Moran and Shaw, 1977). Their very existence is a challenge to the biological species concept, which is based on sexual isolation, hybrid infertility and developmental incompatibility, since all of these criteria may break down within hybrid zones. Bigelow (1965) considered that " the interpretation of hybrid zones remains one of the most difficult of taxonomic problems, despite the striking advances in systematics of recent decades" and subsequent research has still not attained a clear solution to this problem.

The problem is to a large extent a matter of the definition of a species and in particular of what constitutes reproductive isolation. Mayr's (1963) well known definition of the species made lack of interbreeding an important criterion for reproductive isolation. However, Bigelow (1965) proposed that " reproductive isolation should be considered in terms of gene flow and not in terms of interbreeding, since selection will inhibit gene flow between two well integrated gene pools despite interbreeding ". However, a similar criticism can be applied to this criterion of reproductive isolation that Bigelow himself applied to Mayr's. Lack of gene flow cannot be an 
absolute criterion of species status, otherwise it would not be necessary to define introgression as the incorporation of genes of one species into the gene pool of another. Therefore the presence or absence of gene flow cannot be the basis of an operational species definition. However, providing that introgression is limited and does not cause an attenuation of the isolating mechanisms, the taxa involved can be considered good species. This is because those genes or chromosomes which do not disrupt the well integrated harmony of another gene pool, by adverse heterotic or epistatic effects, will be incorporated into the foreign gene pool, provided they can overcome the barrier of selection acting against any non-harmonious gene combinations in the backcross generations. Thus introgression of favourable genes will occur if such genes can be separated by recombination and segregation from those genes which are incompatible with the foreign gene pool. The existence of coadapted gene pools does not preclude the possibility that some genes or chromosomal segments will perform equally well in either genetic background and hence will enhance the genetic variation of the recipient species. Indeed it is feasible that such introgressed genes can actually raise the general fitness of the recipient species. Thus introgressed populations of Drosophila mojavensis, containing genetic material from $D$. arizonensis, have been shown to be significantly fitter on the basis of several measures than either of the parental forms (Nagle and Mettler, 1969). In this case, the experimental introduction of genetic material has increased the fitness of the introgressed species.

Where hybrids are identified on chromosomal criteria, it may be impossible to distinguish between Fl hybrids and backcrosses, unless the two taxa show multiple karyotypic differences. In the study presented here, the two races of Caledia captiva are clearly distinguished by many structural rearrangement differences involving most members of the chromosome complement. The "Torresian" race has an acrocentric-telocentric complement similar to that found in the majority of Acridids. The "Moreton" race, on the other hand, is characterised by submetacentric elements (Shaw, 1976; Moran and Shaw, 1977). However, in some parts of the distribution of this race, particularly near the contact zone (figure 1), there is a high level of secondary polymorphism for acrocentric-telocentric chromosomes, which have been derived from the "Torresian" race by introgression (Moran and Shaw, 1977). A primary polymorphism, which is not the result of introgression, is found for acrocentric and metacentric forms of the $\mathrm{X}$ chromosome within this race and allows a comparison of the rates if autosomal introgression into populations fixed for the alternative sex chromosome morphs.

The high level of chromosomal differentiation found between these races makes this hybrid zone particularly suitable for a comprehensive analysis since the large number of karyotypic differences between the parental forms permits assessment of any restrictions on the production of backcross and F2 progeny, allowing a distinction to be made between hybrid sterility or hybrid breakdown.

A major difficulty in studying a hybrid zone is the problem of attaining adequate sample sizes in restricted areas of the zone. Because there is a steep cline in frequency across a hybrid zone, any sampling strategy which covers too large a part of this cline will necessarily yield an apparent deficit of hybrids due to the Wahlund effect. Interpretation of hybrid deficits in 
samples from hybrid zones must therefore be done with caution. For example, in Spalax ehrenbergii, the hybrid deficits in the 54-58 and 52-58 hybrid zones, which are narrower than the 58-60 zone, in which HardyWeinberg conditions are satisfied (Nevo and Bar-El, 1976), may be due to this fact rather than to enhanced reproductive isolation. In the case of the parapatric races of Caledia in south-east Queensland, the population densities in the vicinity of the hybrid zone are sufficiently high to allow a comprehensive collection of samples to be made. Population densities in this region have been estimated as 3000 adult individuals per hectare (Craft, pers. comm.) and furthermore the distribution of grasshoppers across the zone is uninterrupted by geographical barriers.

\section{Materaials AND Methods}

\section{(i) The Location of the transects}

Two transects have been made, one between "Torresian" populations and "Moreton" populations fixed for the metacentric X and the other between "Torresian" populations and "Moreton" populations fixed for the acrocentric $\mathrm{X}$ in order to locate precisely the position of the hybrid zone and ultimately to analyse its structure. Transect 1 lies between the Gregors Creek "Torresian" population and the Kilcoy "Moreton" metacentric X population (fig. 1). Transect 2, on the other hand, was made between the Bongmuller Creek "Torresian" population and the Spring Valley Creek "Moreton" acrocentric X population. In both cases, the zone of contact was located to within a kilometre. It was not possible to sample Transect 2 in finer detail, because the Mary River lies between the two nearest "Torresian" and "Moreton" populations, at Bell's Bridge and Spring Valley Creek respectively. However, no geographical barrier exists in Transect 1 and it was possible to continue detailed sampling within the 1-k interval (fig. 2). In neither case is the position of contact associated with any abrupt ecological change, but there is a gradual increase in aridity and seasonality in a westward direction between the races (Moran and Shaw, 1977). Although the Mary River runs across Transect 2 and separates the nearest " Torresian" and "Moreton" populations, sampling at other localities on either side of the river (Moran and Shaw, 1977) indicates that it is not a primary geographical barrier separating the races in this region. The two transects are compared only with respect to differential introgression since racially mixed populations were not sampled in Transect 2.

\section{(ii) Location of the contact zone in Transect 1}

The position of the contact zone was located using a sampling strategy with progressively smaller intervals. Originally a $20 \mathrm{~km}$ transect, with $5 \mathrm{~km}$ intervals, was made in an easterly direction from the Gregors Creek site (T1P1) towards Kilcoy. The racial changeover was found to occur between the T1P3 and T1P4 sites. Subsequent sampling at $1-\mathrm{km}$ intervals (A, B, C, D) between T1P3 and T1P4 (see fig. 2), revealed that the T1PA sample was "Torresian" and the T1PB sample "Moreton" in chromosome constitution. 


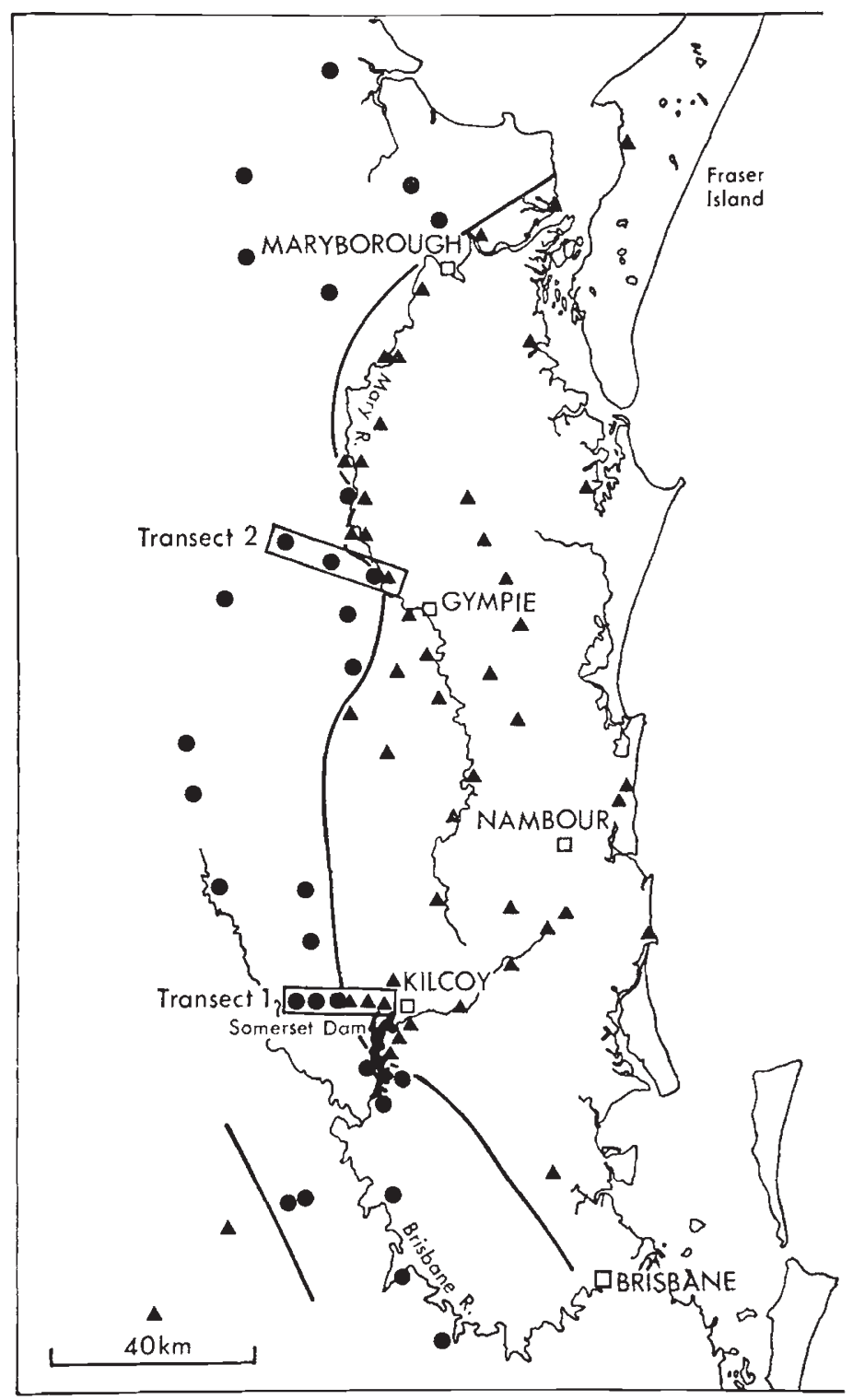

Fig. 1.-The location of Transect 1 and Transect 2 in south-east Queensland. "Moreton" populations are indicated by triangles and "Torresian" populations by circles. The estimated position of the contact zone is shown by the heavy unbroken line.

In January 1977 , at a time of likely maximal population density, a $200 \mathrm{~m}$ interval transect (A1, A2, A3, A4) was made between T1PA and T1PB (fig. 2). Collecting was restricted to a radius of about $20 \mathrm{~m}$ around the end point of each $200 \mathrm{~m}$ interval. About 40 individuals were collected at each location. 


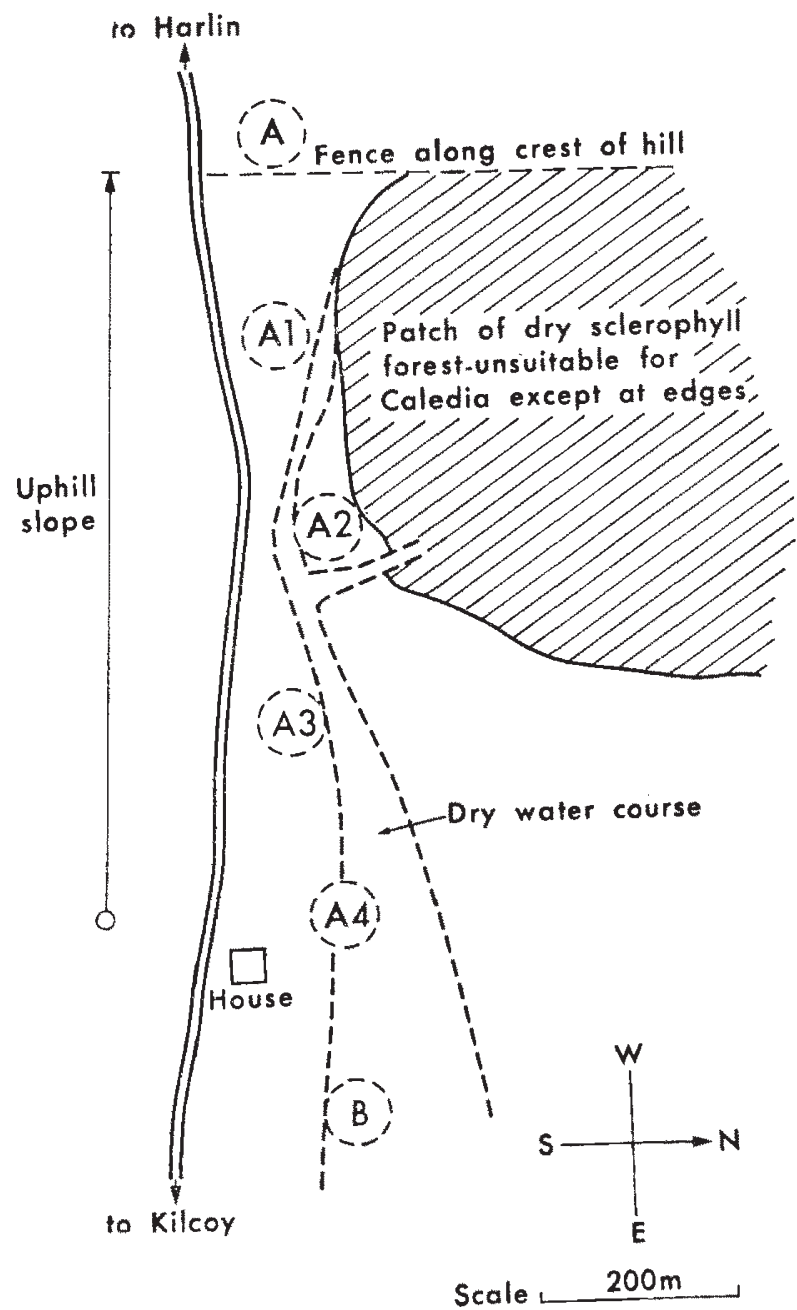

Frg. 2.-A detailed site map of Transect I between TIPA and T1PB, showing the 200-m interval section of this transect.

(iii) Analysis of karyotypes

All grasshoppers were injected with 0.05 per cent colchicine in insect saline and 7-8 hours later, the mid-gut caeca were dissected out, and fixed in $3: 1$ absolute ethanol : glacial acetic acid for use in subsequent mitotic analysis. The testes were removed from all males and fixed prior to colchicine injection. Squash preparations were stained in lactopropionic orcein. Cells from all individuals, except those which were pure "Torresian " in constitution (homozygous acro/telo for all chromosomes), were photographed at a magnification of $\times 2000$ and a karyogram for each individual was prepared (fig. 3). The meiotic pairing relationships of all chromosomes were verified in all F1 hybrid males (see fig. 4 for comparison of F1 hybrids with pure "Torresian" and "Moreton "metaphase 1 plates).

$$
42 / 1-B
$$




\section{Observations}

\section{(i) The number of inversions per individual in Transect 1}

The average number of inverted chromosomes per individual, together with the standard deviation, have been calculated for each of the samples from the transect (table l). These values have been considered separately for males and females because of the difference in chromosome number resulting from the $\mathrm{XO} / \mathrm{XX}$ sex chromosome system. Precise chromosome identification is not required for this method of analysis, but simply a classification into two unambiguous categories. An analysis involving individual chromosome identification will be presented subsequently.

TABLE 1

Average number of inversions per individual in the Transect 1 populations. Note the change between T1PA2, a predominantly "Torresian" sample and T1PA3, a predominantly "Moreton" sample

\begin{tabular}{lrrrrrr} 
& \multicolumn{3}{c}{ Male data } & \multicolumn{3}{c}{ Female data } \\
\cline { 2 - 4 } Population & Mean & S.D. & $\mathrm{N}$ & $\overbrace{\text { Mean }}$ & S.D. & $\mathrm{N}$ \\
T1P3 & 0.12 & 0.33 & 17 & 0.05 & 0.22 & 21 \\
T1PA & 0.85 & 0.93 & 20 & 0.70 & 0.76 & 23 \\
T1PA1 & 3.00 & 4.23 & 15 & 2.32 & 2.94 & 25 \\
T1PA2 & 3.27 & 3.88 & 22 & 2.28 & 3.51 & 18 \\
T1PA3 & 10.33 & 5.03 & 15 & 12.89 & 3.21 & 27 \\
T1PA4 & 13.55 & 1.64 & 20 & 13.09 & 2.17 & 23 \\
T1PB & 14.56 & 2.13 & 9 & 14.29 & 1.21 & 17 \\
T1P4 & 12.92 & 1.44 & 13 & 14.50 & 1.46 & 18
\end{tabular}

For a pure "Torresian" population, the number of inversions per individual is 0. For a pure "Moreton" population, it is more difficult to estimate this parameter because of the primary polymorphism for autosomes 7, 8 and 11 (Moran and Shaw, 1977). However, for a pure population fixed for the metacentric form of the $\mathrm{X}$ chromosome, the individual values range from 16 to 19 for males and 17 to 20 for females, allowing for this primary polymorphism.

An analysis of the difference in the mean number of inversions per individual has been carried out between adjacent populations in the transect. The major change in the mean number of inversions per individual occurs between the samples from T1PA2 and T1PA3 (table 1). These differences are very highly significant for both males and females (table 2). Few of the changes in this parameter in the remaining comparisons between adjacent samples are significant, although there are significant and consistent changes for both sexes between T1P3 and T1PA (tables 1 and 2), which are predominantly "Torresian" populations, which are $1 \mathrm{k}$ apart. This result suggests that selection is still acting strongly against individual " Moreton" chromosomes in the "Torresian" genetic background since neither of these populations is racially mixed nor contains any F1 hybrids. However, there is no evidence of similar selection acting against single "Torresian" chromosomes between TIPB and T1P4, which are $3 \mathrm{~km}$ apart on the "Moreton" side of the zone. Again neither population is racially mixed nor contains F1 hybrids, but there is not a statistically significant increase in the 
average number of inversions per individual as would be expected if selection were acting against individual "Torresian" autosomes. Indeed the male data, if anything, indicate a trend in the opposite direction (tables 1 and 2) between $\mathrm{T} 1 \mathrm{~PB}$ and $\mathrm{T} 1 \mathrm{P} 4$, although this decrease is only marginally significant and not present in the females. Thus if selection is acting against the "Torresian" autosomes in the "Moreton" background, it is much less severe than the selection against individual "Moreton" chromosomes on the "Torresian" side of the zone.

TABLE 2

Pairwise analysis of the differences in the average number of inversions per individual between adjacent populations by means of "Students" $\mathrm{t}$ test. Where variances are significantly different by the variance ratio $F$ test,* a modified $\mathrm{t}$ test (Bailey, 1959) has been applied

\begin{tabular}{lccccccc} 
& \multicolumn{3}{c}{ Male data } & & \multicolumn{3}{c}{ Female data } \\
\cline { 2 - 5 } Comparison & $t$ & d.f. & $\mathbf{P}$ & & $\overbrace{t}$ & d.f. & $\mathbf{P}$ \\
3-A & 3.276 & $24^{*}$ & $<0.01$ & & 3.925 & $26^{*}$ & $\ll 0.01$ \\
A-A1 & 1.870 & $15^{*}$ & n.s. & 2.660 & $27 *$ & $<0.05$ \\
A1-A2 & 0.200 & 35 & n.s. & & 0.041 & 41 & n.s. \\
A2-A3 & 4.818 & 35 & $\ll 0.01$ & 10.465 & 43 & $\ll 0.01$ \\
A3-A4 & 2.386 & $16^{*}$ & $<0.05$ & 1.567 & $45^{*}$ & n.s. \\
A4-B & 1.399 & 27 & n.s. & & 2.225 & $36^{*}$ & $<0.05$ \\
B-4 & 2.162 & 20 & $<0.05$ & & 0.462 & 33 & n.s.
\end{tabular}

This interpretation of differential selection is supported by a comparison of the observed average number of inversions in samples from either side of the hybrid zone. For example in T1P3, which is only $1.5 \mathrm{~km}$ from the centre of the zone, the observed number of inversions (table 1 ) is very close to the expected value of 0 for a pure "Torresian" population. On the other hand, on the "Moreton" side of the zone at TIP4, the observed average number of inversions (table 1) is about three below the minimal expected value of 16 or 17 , even though this locality is $3.5 \mathrm{~km}$ from the centre. Therefore "Moreton" chromosomes are rapidly eliminated on the "Torresian" side of the zone, whereas the "Torresian" autosomes persist on the "Moreton" side. This evidence further supports the interpretation made previously (Moran and Shaw, 1977), that a considerable amount of the chromosomal variability in the "Moreton" race is attributable to the one-way introgression of "Torresian" chromosomes into the "Moreton" race,

\section{(ii) F1 hybrids and parental types in the contact zone}

The individuals from each sample across the transect have been classified into three categories (see figs 3 and 4 for examples). These are:

(i) "Torresian" (pure and backcross derivatives)

(ii) F1 hybrids

(iii) "Moreton" (pure and backcross derivatives)

The diagnostic characteristic of F1 hybrids is, of course, maximal chromosomal heterozygosity. However, because backcross individuals are frequent, some allowances must be made for FI individuals derived by hybridisation 
between " introgressed" individuals of the two races (see fig. 3). Hybrids derived from such matings will be homozygous for one or more diagnostic chromosomal pairs. For example, in T1PAl, 10 of the 13 "Torresian" males had one or more inverted chromosomes, with an average of 1.9 inversions per backcross derived individual. Similarly, 14 of the 22 " Torresian "females from the same sample had an average of $2 \cdot 3$ inversions per individual. Similar statistics for the other predominantly "Torresian" populations are presented in table 3. Consequently a small proportion of the individuals classified as backcross derivatives may in fact be Fl hybrids and vice versa. In practice, however, the proportion of such ambiguous individuals is very low and unlikely to affect the validity of the data. It is more difficult to assess this effect on the "Moreton" side of the zone, partly because of the primary polymorphism for chromosomes 7, 8 and 11 and partly because there are fewer restrictions on the occurrence of new segregants on the "Moreton" side of the zone as a subsequent section will demonstrate.

TABLE 3

Average number of inversions per "Torresian" backcross individual. The numbers of backcross derivatives and pure "Torresian" individuals in each sample are also shown

\begin{tabular}{|c|c|c|c|c|c|c|c|c|}
\hline \multirow[b]{2}{*}{ Population } & \multicolumn{4}{|c|}{ Males } & \multicolumn{4}{|c|}{ Females } \\
\hline & No. inv. & S.D. & $\mathrm{N}$ & $\begin{array}{l}\text { No, pure } \\
\text { "Torresian" }\end{array}$ & No. inv. & S.D. & $\mathrm{N}$ & $\begin{array}{l}\text { No. pure } \\
\text { "Torresian" }\end{array}$ \\
\hline TIPA & $1 \cdot 54$ & $0 \cdot 69$ & 11 & 9 & $1 \cdot 33$ & 0.49 & 12 & 11 \\
\hline TlPAl & $1 \cdot 90$ & $1 \cdot 10$ & 10 & 3 & $2 \cdot 29$ & 1.73 & 14 & 8 \\
\hline T1PA2 & $2 \cdot 43$ & 1.51 & 7 & 8 & 1.66 & 0.82 & 6 & 7 \\
\hline
\end{tabular}

The racial frequencies, based on total genome classification, show a steep clinal change (fig. 5, table 4 ), with the major change in frequency occurring in the 200-m interval between T1PA2 and T1PA3. T1PA2 contains $72 \cdot 5$ per cent "Torresian" individuals, whereas T1PA3 contains 73.8 per cent "Moreton" individuals. In other words, there is a jump of 65.4 per cent in the frequency of "Torresian " individuals and $68 \cdot 8$ per cent in the frequency of "Moreton" individuals between T1PA2 and T1PA3.

The breeding structure of the racially-mixed populations from T1PAl to T1PA4 has been analysed by means of Hardy-Weinberg analysis. In T1PAl and T1PA3, the chi-square values ( 1 d.f.) of $11 \cdot 14$ and $4 \cdot 13$ respectively are significant. However, in these two cases, the skewed chromosome frequencies have led to very small expected values for the least frequent genotypic category and the tests are therefore statistically non-conservative (Lewontin and Felsenstein, 1965). On the other hand, in T1PA2 and T1PA4, the chi-square values of 1.21 and 0.03 respectively are not significant. In these cases, and probably in the former two cases, there is random mating between the races and normal survival of the Fl progeny. Laboratory crosses have also demonstrated that there are no pre-mating reproductive barriers between the "Torresian" and "Moreton" races and have demonstrated the normal viability of the Fl progeny (Moran, 1978). Given random mating between the races and normal viability of the $\mathrm{Fl}$, the complete change from one race to the other over $1 \mathrm{k}$, with an abrupt change in the 

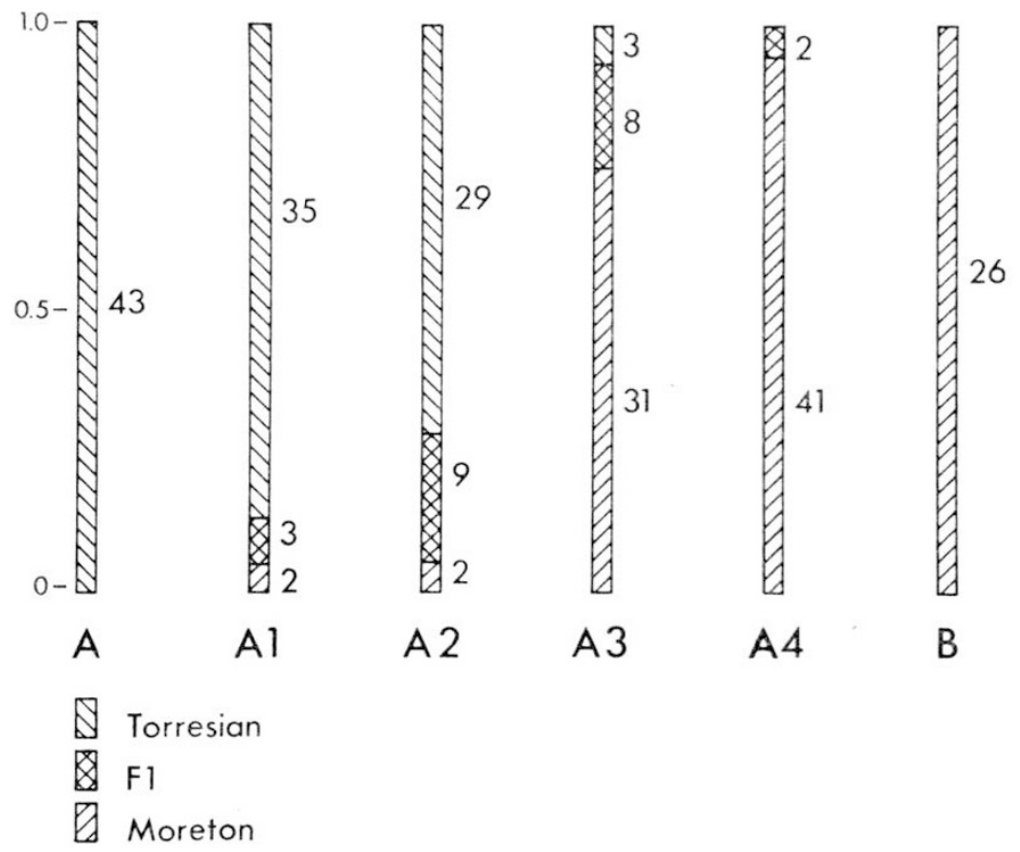

A 2

A3

A4

B

FIG. 5.-Racial frequencies in the 200-m interval section of Transect 1 . The numbers of parental and F1 hybrid individuals sampled are shown beside each frequency histogram.

central $200 \mathrm{~m}$ interval, can only be explained in terms of hybrid sterility or hybrid breakdown.

\section{(iii) The chromosomes in the contact zone}

If the frequency of individual chromosomes is followed across the transect, a high level of resolution can be obtained of the genetic changes which are taking place, particularly when consideration is also taken of the racial changes based on total genome analysis. It is possible to compare both the frequencies of a given chromosome between the different points in the transect and also to compare the relative frequencies of different chromosomes at the same point (Table 4).

As expected from the previous analysis of racial frequencies, the major change in the chromosome frequencies occurs between T1PA2 and TIPA3. In this interval of only $200 \mathrm{~m}$, the following changes in frequency occur:

$\begin{array}{cccccccccc}1 & 2 & \mathrm{X} & 4 & 5 & 6 & 7 & 8 & 10 & 11 \\ 0.452 & 0.551 & 0.688 & 0.465 & 0.587 & 0.599 & 0.236 & 0.260 & 0.538 & 0.305\end{array}$

Glearly there are two major groups, with the small group, consisting of chromosomes 7,8 and 11, having frequency changes in this interval of approximately 30 per cent or less. The remaining chromosomes show changes of greater than 45 per cent. It should be noted that the highest change in frequency involves the $\mathrm{X}$ chromosome. Further the $\mathrm{X}$ chromosome shows the most rapid diminution of frequencies in the populations on either side of these central populations. On the other hand, the smaller 
ㅎำ

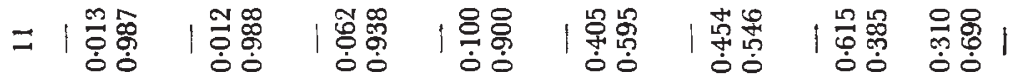

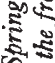

ธิ

赵赵

补

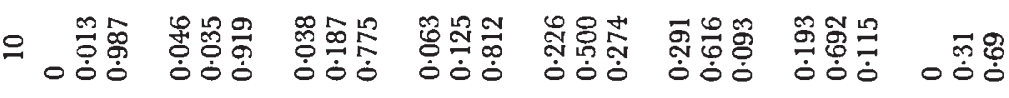

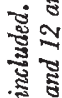

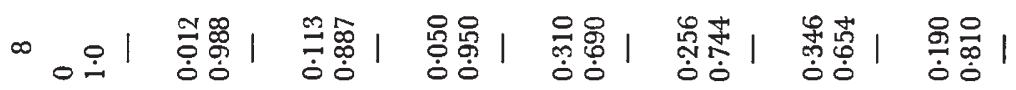

옹

तิ

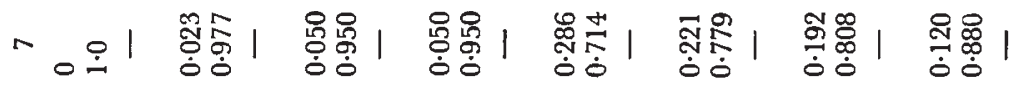

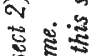

。

要密芯

政

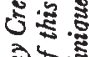

ङ

纹

है 3

$+\frac{2}{2}+\frac{2}{2}$

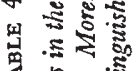

क्षे

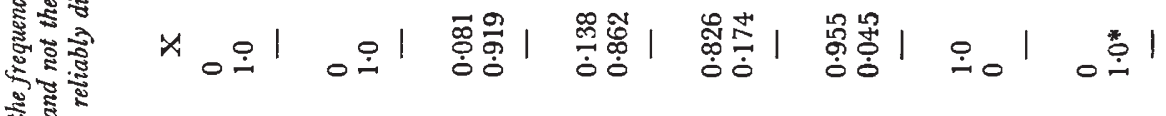

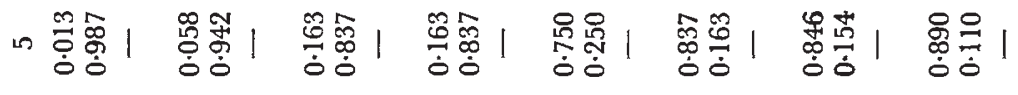

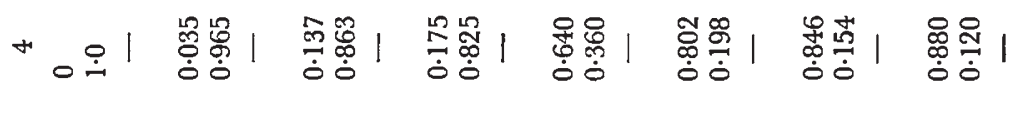

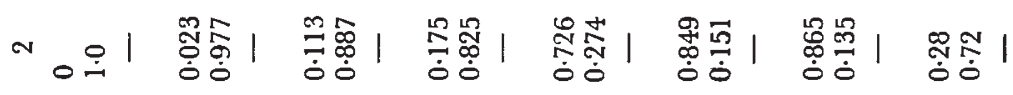

密定

s:

.

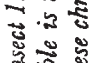

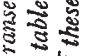

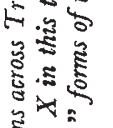

窟

一 。ำ 綰

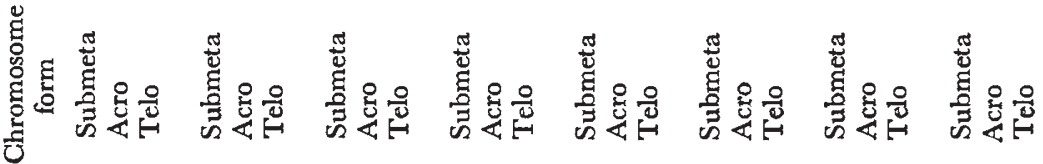

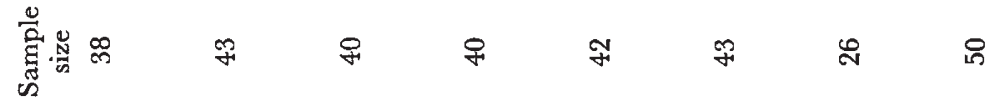

ะะ

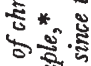

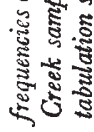

要

总

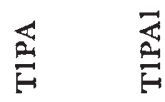

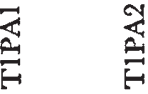

娄 总

$\stackrel{\Xi}{\sharp}$

Eี

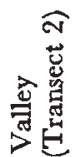


frequency changes for chromosomes 7, 8 and 11 are correlated with lower frequencies of submetacentric (7 and 8) and acrocentric (11) chromosomes on the "Moreton" side of the zone. On the basis of the geographical distribution of the forms of these chromosomes (Moran and Shaw, 1977), it has previously been concluded that there are primary polymorphisms for these chromosomes, similar to the acrocentric-submetacentric polymorphism for chromosome 10. In other words, the acrocentric classes of chromosomes for 7 and 8 and the telocentric class for chromosome 11 (table 4) contain "Moreton" and "Torresian" forms which cannot be distinguished by the cytological techniques employed in this study.

Hardy-Weinberg analysis of the autosomal genotypic data (table 5) has revealed only four significant deviations among the 54 tests performed. Again the few significant chi-square values can be attributed to small cell expectations, usually less than one, resulting from skewed chromosomal frequencies. In other words, the non-conservative nature of the test leads to spuriously significant values.

TABLE 5

Hardy-Weinberg analysis of chromosomal genotypic data for the Transect 1 samples. In both cases of highly significant $\chi^{2}$ values, the tests are non-conservative because of very small expected values. $A$ three allele test has been applied to the chromosome 10 data and the degrees of freedom are shown in parenthesis after the chi-square value

\begin{tabular}{|c|c|c|c|c|c|c|c|c|c|}
\hline \multirow[b]{2}{*}{ Population } & \multicolumn{9}{|c|}{ Chromosome } \\
\hline & 1 & 2 & 4 & 5 & 6 & 7 & 8 & 10 & 11 \\
\hline T1PA & $\begin{array}{r}0.08 \\
\text { n.s. }\end{array}$ & $\begin{array}{r}0.03 \\
\text { n.s. }\end{array}$ & $\begin{array}{r}0.08 \\
\text { n.s. }\end{array}$ & $\begin{array}{r}0.15 \\
\text { n.s. }\end{array}$ & $\begin{array}{r}0.58 \\
\text { n.s. }\end{array}$ & $\begin{array}{r}0.03 \\
\text { n.s. }\end{array}$ & $\begin{array}{c}0.01 \\
\text { n.s. }\end{array}$ & $\begin{array}{c}0.34 \text { (I) } \\
\text { n.s. }\end{array}$ & $\begin{array}{c}0.01 \\
\text { n.s. }\end{array}$ \\
\hline T1PA1 & $\begin{array}{r}6 \cdot 78 \\
* *\end{array}$ & $\begin{array}{c}5 \cdot 55 \\
*\end{array}$ & $\begin{array}{r}2 \cdot 27 \\
\text { n.s. }\end{array}$ & $\begin{array}{r}1 \cdot 20 \\
\text { n.s. }\end{array}$ & $\begin{array}{r}0.58 \\
\text { n.s. }\end{array}$ & $\begin{array}{c}0 \cdot 11 \\
\text { n.s. }\end{array}$ & $\begin{array}{c}0.61 \\
\text { n.s. }\end{array}$ & $\begin{array}{c}1.39(1) \\
\text { n.s. }\end{array}$ & $\begin{array}{c}0 \cdot 18 \\
\text { n.s. }\end{array}$ \\
\hline T1PA2 & $\begin{array}{r}0.18 \\
\text { n.s. }\end{array}$ & $\begin{array}{r}0.72 \\
\text { n.s. }\end{array}$ & $\begin{array}{c}0.06 \\
\text { n.s. }\end{array}$ & $\begin{array}{c}0.004 \\
\text { n.s. }\end{array}$ & $\begin{array}{c}0.004 \\
\text { n.s. }\end{array}$ & $\begin{array}{r}0 \cdot 11 \\
\text { n.s. }\end{array}$ & $\begin{array}{l}8.97 \\
* * *\end{array}$ & $\begin{array}{l}0.42(1) \\
\text { n.s. }\end{array}$ & $\begin{array}{r}1 \cdot 11 \\
\text { n.s. }\end{array}$ \\
\hline T1PA3 & $\begin{array}{r}0.04 \\
\text { n.s. }\end{array}$ & $\begin{array}{r}2 \cdot 06 \\
\text { n.s. }\end{array}$ & $\begin{array}{r}0.53 \\
\text { n.s. }\end{array}$ & $\begin{array}{r}0 \cdot 10 \\
\text { n.s. }\end{array}$ & $\begin{array}{r}0.28 \\
\text { n.s. }\end{array}$ & $\begin{array}{r}0 \cdot 19 \\
\text { n.s. }\end{array}$ & $\begin{array}{r}0.55 \\
\text { n.s. }\end{array}$ & $\begin{array}{c}5 \cdot 18(3) \\
\text { n.s. }\end{array}$ & $\begin{array}{c}0.006 \\
\text { n.s. }\end{array}$ \\
\hline T1PA4 & $\begin{array}{r}0.04 \\
\text { n.s. }\end{array}$ & $\begin{array}{c}5 \cdot 76 \\
*\end{array}$ & $\begin{array}{r}0.29 \\
\text { n.s. }\end{array}$ & $\begin{array}{r}0 \cdot 29 \\
\text { n.s. }\end{array}$ & $\begin{array}{r}0.75 \\
\text { n.s. }\end{array}$ & $\begin{array}{c}0.008 \\
\text { n.s. }\end{array}$ & $\begin{array}{c}0.42 \\
\text { n.s. }\end{array}$ & $\begin{array}{c}5 \cdot 24(3) \\
\text { n.s. }\end{array}$ & $\begin{array}{r}0.27 \\
\text { n.s. }\end{array}$ \\
\hline T1PB & $\begin{array}{r}0.44 \\
\text { n.s. }\end{array}$ & $\begin{array}{c}0.63 \\
\text { n.s. }\end{array}$ & $\begin{array}{r}0.34 \\
\text { n.s. }\end{array}$ & $\begin{array}{c}0.34 \\
\text { n.s. }\end{array}$ & $\begin{array}{r}1.59 \\
\text { n.s. }\end{array}$ & $\begin{array}{r}1.48 \\
\text { n.s. }\end{array}$ & $\begin{array}{c}0.92 \\
\text { n.s. }\end{array}$ & $\begin{array}{c}1.31(2) \\
\text { n.s. }\end{array}$ & $\begin{array}{r}3 \cdot 18 \\
\text { n.s. }\end{array}$ \\
\hline
\end{tabular}

The behaviour of the $\mathrm{X}$ chromosome in the contact zone warrants further comment. Apart from displaying the largest frequency change in the 200-m interval between T1PA2 and T1PA3, it is the only chromosome to achieve fixation of the "Torresian" acrocentric or the "Moreton" metacentric forms respectively at T1PA and T1PB, which lie at opposite ends of the $1 \mathrm{k}$ transect. Thus the $\mathrm{X}$ shows the sharpest change in the central interval and the most rapid change overall. Further the $\mathrm{X}$ chromosome has only once been found in a foreign autosomal background other than in an F1 hybrid. This involved a female from the T1PA4 sample, 
which was found to be heterozygous for the $\mathrm{X}$ chromosome, but was homozygous for the "Moreton" form of chromosomes 4, 5 and 6. Although this individual was scored as a "Moreton" backcross derivative, it could also have arisen from a cross between a "Torresian" backcross derivative and a "Moreton" individual. However, despite this single exception, it is notable that all 11 other cases of X chromosome heterozygosity in the contact zone samples are restricted to F1 hybrids. Since it is also clear that the $\mathrm{X}$ chromosomes do not introgress in either direction (Moran and Shaw, 1977) it seems likely that they play a major role in maintaining the integrity of the "Torresian" and "Moreton" races.

\section{(iv) Gametic disequilibrium between chromosomes}

For two loci, each with two alleles, there are nine genotypic categories. Therefore, an adequate statistical analysis of non-random associations between two loci (or non-homologous chromosomes) requires large sample sizes, particularly when the gene frequencies are very skewed. In this case, the analysis of non-random associations between non-homologous chromosomes in the populations sampled from the hybrid zone must overcome both the problem of skewed chromosome frequencies and relatively small sample sizes.

The statistical analysis used here consists of a "genic" independence chi-square test, which has been applied to all possible pairwise combinations of chromosomes 1, 2, 4, 5, 6, 10 and 11 for populations T1PA1, TIPA2, TIPA3, and TIPA4. The "Moreton" acrocentric and metacentric forms of chromosome 10 have been pooled for this analysis. All cells with an expectation of less than one in the independence test matrix have been pooled with the adjacent cell with the smallest expectation, until all expectations less than one have been pooled and the total pooled expectation is greater than one. This strategy ensures that the test is statistically conservative (Lewontin and Felsenstein, 1965). All cases of statistically significant departures from non-randomness are due to disequilibria resulting from an excess of parental combinations in the double homozygous and double heterozygous categories and a deficiency of the recombinant classes. However, the contribution of the less frequent parental double homozygous type is inevitably lost because of the pooling strategy.

There is a striking difference in the pattern of gametic disequilibrium between non-homologous chromosomes in populations on either side of the contact zone (table 6). Thus T1PAI and TIPA2, which are predominantly "Torresian", have strong non-random associations, which affect all of the tested chromosomes. Although not all pairwise combinations show statistically significant disequilibria, all display the same trend with an excess of parental double homozygous and hybrid double heterozygous types. However, there is no consistent pattern of association in T1PA3 and TIPA4, which are predominantly "Moreton" in constitution, except for the chromosome 1-2 combination, which shows statistically significant departures from non-randomness in both populations. The other departures in these populations are few and only marginally significant, compared with the many highly significant associations in T1PAl and T1PA2. The change from populations with many significant non-random associations to those with few detectable disequilibria occurs between T1PA2 and T1PA3. This 


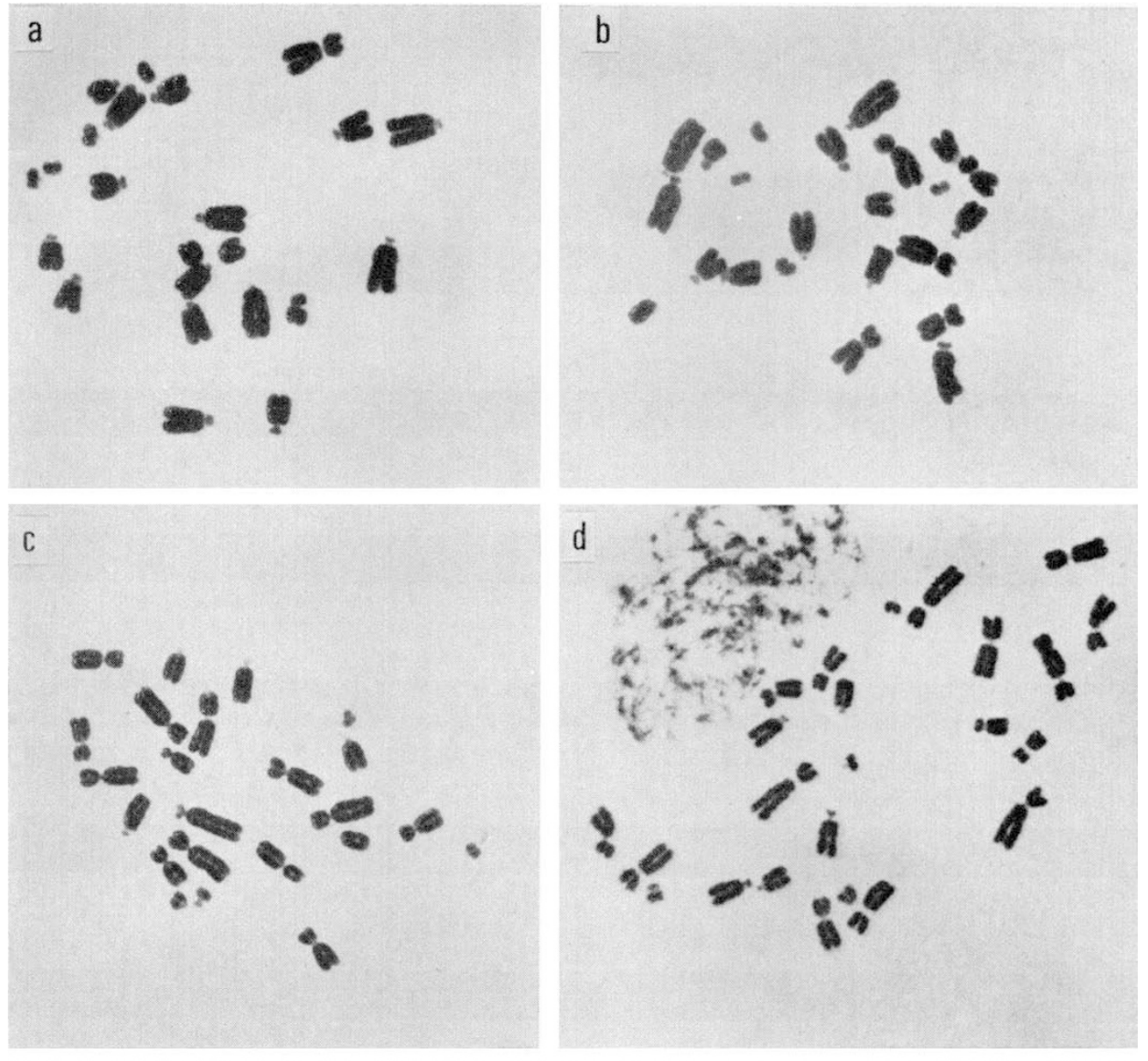

$12 \times 456789910 \quad 11 \quad 12$

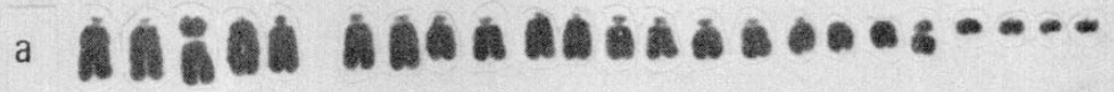

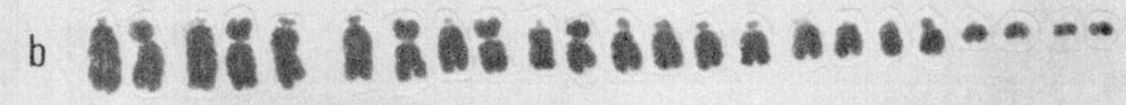

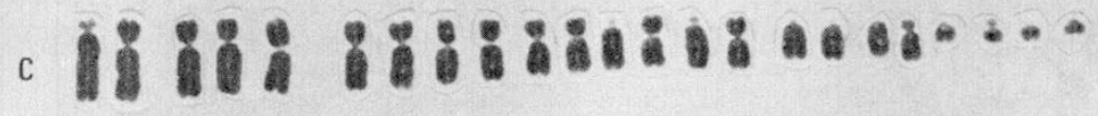

d 
a
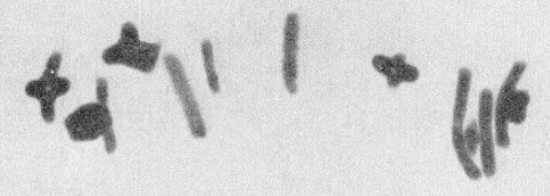

b

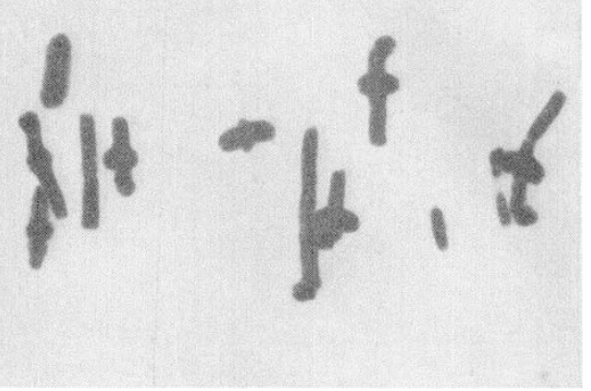

d

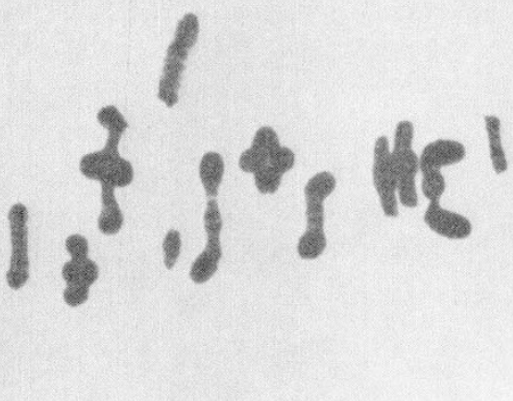

Plate II, FIG. 4

FIG. 3.- Mitosis in individuals from the hybrid zone. (a) "Torresian" backcross derivative -contains submetacentric chromosome 2, and metacentric chromosome 10 from the "Moreton" race. (TIPA Male 4). (b) Fl hybrid carrying the "Torresian" acrocentric X chromosome. Structurally heterozygous for chromosomes 1, 2, 4, 5, 6 and 10 (see also Fig. 3c for meiosis of this individual). (T1PA2 Male 15.) (c) "Moreton" backcross derivative. Heterozygous for chromosomes 1, 10 and 11. (TIPA4 Male 15.) (d) "Moreton" individual. Structurally heterozygous for chromosomes 8 and 10 . However, these variant forms represent a primary polymorphism within the "Moreton" race. (TlBP Female 2.) Karyograms of each of these individuals are also presented.

FIG. 4.-Meiosis in males from the hybrid zone. (a) Pure "Torresian" male. Note the terminal or subterminal position of all centromeres and the presence of interstitial chiasmata. (TlPAl Male 4.) (b) Fl hybrid with "Torresian" acrocentric X. Note the heteromorphic structure of six of the bivalents, resulting from flexure of the short arm of the submetacentric chromosomes. (T1PA2 Male 16.) (c) F1 hybrid with "Torresian" acrocentric X (see also fig. 3b). Flexture of the short arm of submetacentric chromosomes apparent in five of the six structurally heterozygous bivalents. (T1PA2 Male 15.) (d) "Moreton" individual. Note homozygosity for flexed short arms in six of the chromosomes. Chromosomes 7, 8 and 9 are homozygous for acrocentric or telocentric chromosomal forms. The heteropycnotic $\mathrm{X}$, although submetacentric, does not show flexure in this cell, although this is often observed in other cells from the same individual. (T1PA3 Male 3.) 
TABLE 6

Gametic disequilibrium analysis of pairwise combinations of chromosomes in the four central samples from Transect 1. A genic independence chi-square test has been used

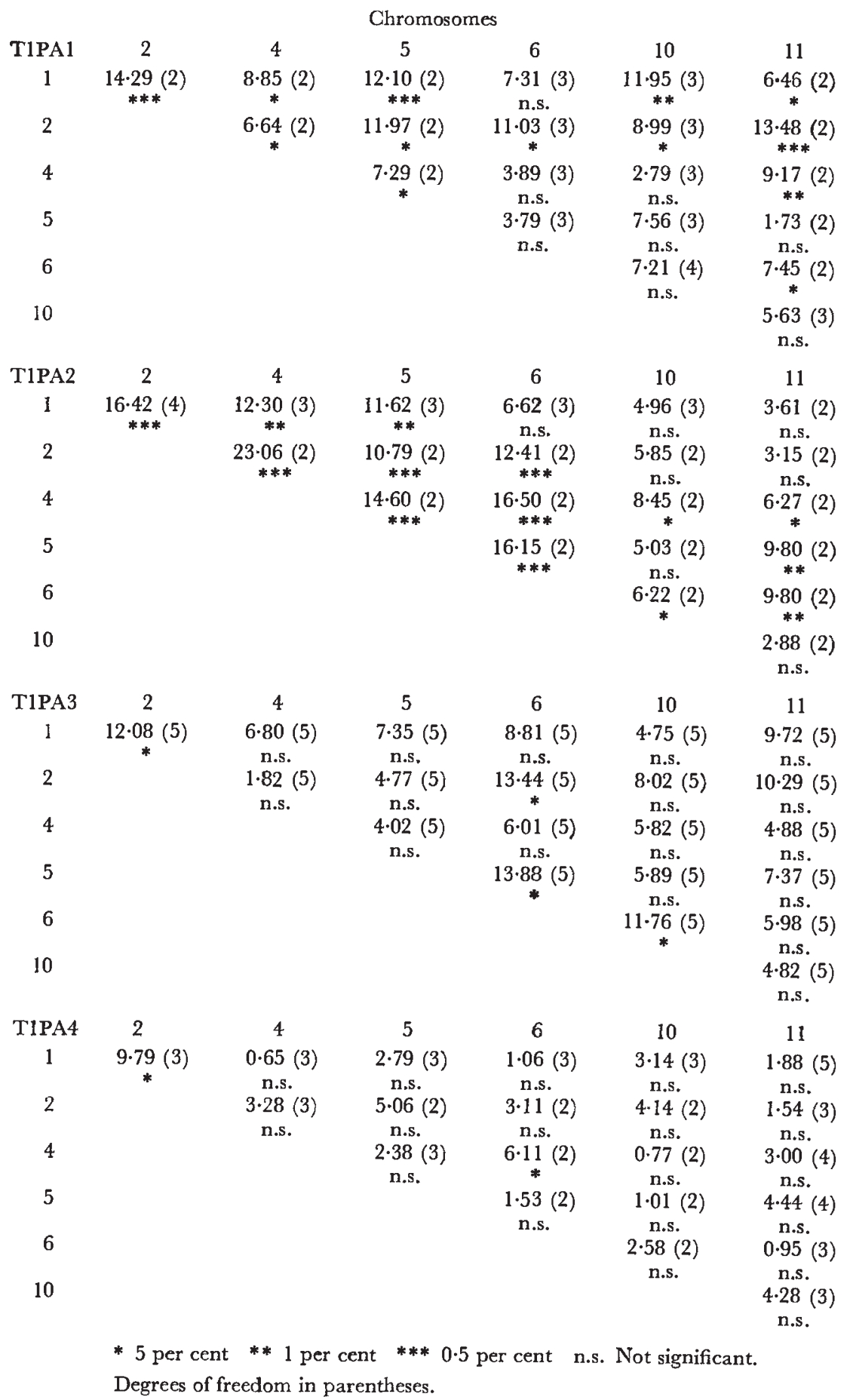


corresponds to the previously described change from a predominantly "Torresian" population to one which is mainly "Moreton" in constitution, with a simultaneous large change in the frequencies of all chromosomal morphs.

The "recombinant" chromosomal genotypes consist of those pair-wise categories in which one chromosome is heterozygous and the other homozygous (e.g. $\mathrm{T} / \mathrm{M}, \mathrm{T} / \mathrm{T})$ and those in which both are homozygous for a combination not found in the parental types (e.g. T/T, M/M). These genotypes will be produced either by backcrossing or the crossing inter se by the Fl hybrids. The deficit in the recombinant categories in the predominantly "Torresian" populations suggests that there is a severe restriction on the production of $\mathrm{F} 2$ and backcross progeny in these populations, although the data clearly show that it is not an absolute restriction. On the other hand, the general lack of associations between autosomal forms on the "Moreton" side of the contact zone demonstrates that there is much less restriction to the formation of new autosomal combinations in this case. However, in both types of populations, with one possible exception, all females heterozygous for the $\mathrm{X}$ chromosome are $\mathrm{Fl}$ hybrids. Furthermore, the homozygous $\mathrm{X}$ chromosome pair in the females has been found to be diagnostic of their racial type in the hybrid zone populations. In other words, homozygous metacentric X individuals are "Moreton" and the homozygous acrocentric $\mathrm{X}$ females are always otherwise classifiable as "Torresian", The Xautosome associations in the females have not been tested because of the reduction in sample size when the male data are removed. Nevertheless, it is clear that there are barriers to the formation of new $\mathrm{X}$ chromosomeautosome combinations.

Severe selection is required to maintain associations between even a single pair of non-homologous chromosomes in the face of independent segregation. Further the recombination load increases rapidly for each additional chromosome pair. Hybrid breakdown is one possible means of restricting the formation of new chromosomal combinations on the "Torresian " side of the zone and is the only mechanism likely to maintain so many related non-random associations, since hybrid infertility would generate similar disequilibria on the "Moreton" side. However the lack of nonrandom associations on the "Moreton" side of the zone implies that backcross breakdown is less severe and selective autosomal introgression could therefore occur. Laboratory crosses, coupled with cytological analysis of meiosis in Fl hybrid males, have provided independent evidence of F2 breakdown (Moran, 1978).

The results of the gametic disequilibrium analysis on these four populations at the contact zone are consistent with the pattern of one-way introgression of chromosomes from the "Torresian" into the "Moreton" race. Furthermore, asymmetrical hybrid breakdown would not only give rise to the observed pattern of disequilibria and the restrictions on introgression, but would also maintain a narrow hybrid zone.

\section{Discussion}

(i) The "Moreton" $X$ chromosomes and introgression

The nature of the geographical distribution of the acrocentric and, metacentric morphs of the "Moreton" X chromosomes (Moran and Shaw, 
1977) permits a comparison of the rates of introgression of "Torresian" autosomes into "Moreton" populations fixed for either of these forms of the $\mathrm{X}$ chromosome. This comparison is particularly relevant since the data presented here have shown that the $\mathrm{X}$ chromosome frequency changes within the hybrid zone are more extreme than the changes in autosomal frequency, implying that the $\mathrm{X}$ chromosome is an important factor in maintaining isolation between these taxa. A previous study (Moran and Shaw, 1977) has already demonstrated differences in the frequency of introgression of particular autosomes (fig. 6a). The effects of the alternative "Moreton" X chromosome morphs on regulating introgression of "Torresian" autosomes are now discussed. The comparisons can be best made between the Spring Valley Creek population (Moran and Shaw, 1977), which is fixed for the acrocentric $X$ and T1PAB (see table 4), and are in approximately equivalent positions relative to the contact zone (see fig. 1 for geographical locations). The introgressed acrocentric-telocentric

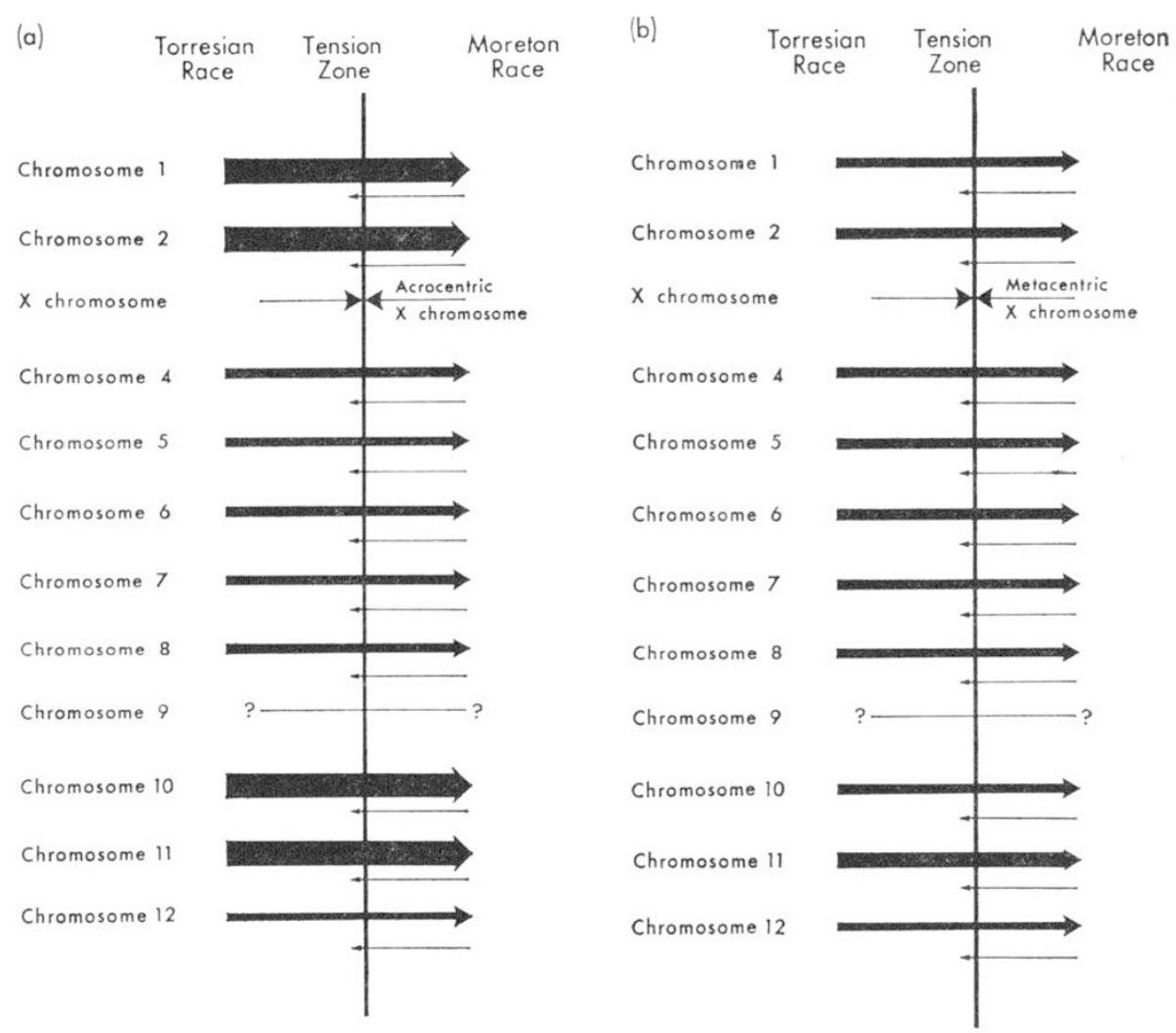

FIG. 6.-Diagrammatic representation of differential introgression into the "Moreton" race. (a) Introgression into "Moreton" acrocentric X populations, showing the high rate of introgression of chromosomes $1,2,10$ and 11 into the "Moreton " populations, as in Transect 2. (b) Introgression into "Moreton" metacentric X populations showing a more uniform rate of autosomal introgression from the "Torresian" race, as in Transect 1. 
morphs of chromosomes 1,2, 10 and 11 are found at a much higher frequency in the Spring Valley Creek population than in T1PB. However, the introgressed morphs of chromosomes 4, 5, 6, 7 and 8 have similar frequencies between the two types of populations. This difference between acrocentric $\mathrm{X}$ and metacentric $\mathrm{X}$ populations is consistently observed in other "Moreton" populations collected in the vicinity of the contact zone (Moran and Shaw, 1977). A simplified diagrammatic representation of this differential introgression has been made in fig. 6. The large arrows for chromosome 1, 2, and 11 (fig. 6) represent a higher frequency of introgression of these chromosomes into the acrocentric $\mathrm{X}$ populations both relative to the other autosomes in these populations and to the similar autosomes in the metacentric $\mathrm{X}$ populations.

An analysis of chromosomal gametic disequilibrium in two "Moreton" acrocentric $\mathrm{X}$ populations from the vicinity of the contact zone (Moran, 1978), similar to that performed on the Transect 1 data, has revealed only one significant result in 42 tests. Thus the analysis of non-random autosomal associations in these acrocentric $\mathrm{X}$ populations agrees with this previously presented results in the "Moreton " metacentric X populations

A role for the $\mathrm{X}$ chromosome in maintaining reproductive isolation between parapatrically distributed taxa is suggested by several other cases where chromosomal races are distinguished by $\mathrm{X}$ chromosome rearrangements alone. Examples are found in the Didymuria violescens complex (Craddock, 1971, 1975), the Viatica group of Morabine grasshoppers (White et al., 1967; White et al., 1969; Mrongovius, 1975) and in the Alpine grasshopper Podisma pedestris (Hewitt, 1975), where X-autosome fusions are the sole or major rearrangement difference. However, in these cases, the F1 hybrid males cannot be chromosomally distinguished from the parental males and thus cannot suffer from infertility resulting from the structural rearrangement. In one case which has been tested, male hybrids of $\mathrm{P}(24 \mathrm{XY})$ and viatica 17 displayed only a 3 per cent increase in the frequency of asynapsis over controls and the fecundity of the hybrids was normal (Mrongovius, 1975). Similarly the structural rearrangement differences of the X chromosome between the "Moreton" and "Torresian " races of Caledia captiva cannot, of themselves, depress the fertility of the hybrids, since the males have only one $\mathrm{X}$ chromosome and crossing-over is not expected to occur in the heterozygous inverted $\mathrm{X}$ segments of the females. The role of the $\mathrm{X}$ chromosome as an isolating mechanism must therefore be in terms of epistatic interactions with the autosomes in the F2 or backcross generations.

\section{(ii) A model of hybrid breakdown in a contact zone}

A deterministic model of hybrid breakdown in a contact zone has been produced to analyse the genetic load and the change in racial frequency per generation with any given initial frequency of racial types. The model (see table 7) assumes random mating between the races, normal viability and fertility of the F1 hybrids and several different regimes of F2 and backcross breakdown. A further important assumption is that survival of the backcross progeny is directly related to their degree of genetic resemblance to the parents, although this relationship may differ on either side of the hybrid zone. This justifies the lumping of surviving backcross progeny with the parental types for extrapolations beyond the second generation. 


\section{TABLE 7}

$A$ deterministic model of the effects of hybrid breakdown in a contact zone. The model allows the calculation of the genetic load and the expected change in racial frequencies at any given initial frequency. The model assumes random mating between the races and their derivatives and determines the consequences of breakdown in the second generation after contact. It is possible to extrapolate to subsequent generations. The extent of breakdown, which in this case means effective lethality due to developmental incompatibility, is denoted by the selective coefficients $\mathrm{s}_{1}, \mathrm{~s}_{2}$ and $\mathrm{s}_{3}$

TT

$p$

$\mathrm{TT}$

$p^{2}$

T

MM

$q$

Gen 1<smiles>[Mg][Mg]</smiles>

MM

$q^{2}$

Gen 2

\begin{tabular}{|c|c|c|c|c|c|}
\hline $\mathrm{TT}$ & T Backcross & F2 & $\mathrm{TM}(\mathrm{F} 1)$ & M Backcross & MM \\
\hline$p^{4}$ & $4 p^{3} q$ & $4 p^{2} q^{2}$ & $2 p^{2} q^{2}$ & $4 p q^{3}$ & $q^{4}$ \\
\hline 1 & $1-s_{1}$ & $1-s_{2}$ & 1 & $1-s_{3}$ & 1 \\
\hline \multicolumn{6}{|c|}{ Load $=4 p^{3} q s_{\mathrm{I}}+4 p^{2} q^{2} s_{2}+4 p q^{3} s_{3}$} \\
\hline \multicolumn{6}{|c|}{$\hat{q}=\frac{q^{4}+4 p q^{3}\left(1-s_{3}\right)+p^{2} q^{2}+\frac{4}{3} p^{2} q^{2}\left(1-s_{2}\right)}{1-4 p^{3} q s_{1}-4 p^{2} q^{2} s_{2}-4 p q^{3} s_{3}}$} \\
\hline
\end{tabular}

With complete F2 and backcross breakdown, (1) there is a symmetrical relationship for both genetic load and the change in racial frequency (fig. 7a and b, closed circles) about the equivalence point of the contact zone, where both races occur with equal frequency and make an equal contribution to the derivatives. At this mid-point, the maixmum genetic load of 75 per cent occurs and the expected change in racial frequency is 0. However, the frequencies on either side of the equilibrium point are unstable and will move towards the nearest absorbing boundary at 0 or 1.0 , with each generation of breakdown, unless balanced by migration. The rate of change is highest for frequencies around 0.25 and 0.75 . The instability of these frequencies will tend to reduce the genetic load in the zone overall and in geographical terms will cause a reduction in its width. Since there must always be an equivalence point in the contact zone, a stable narrow zone will be maintained provided there is some migration. The alternative is extinction of both races at the point of contact.

The second example presented in fig. 7 (open squares) demonstrates the effect of unilateral backcross breakdown, with complete survival of one type of backcross progeny and complete elimination of the other type. The model is oversimplified in that all of the viable backcross products have been pooled with the parental type with which the backcross was made. In practice, all such backcross products would not have been classified in this way, since it is possible to produce individuals having a greater resemblance to Fl hybrids than to the parental type. Despite this limitation of the model, the effect of asymmetrical breakdown is to displace the equilibrium frequency and point of maximum genetic load away from 0.5. Again the equilibrium is unstable and frequencies on either side of the null point will move towards the absorbing boundaries. 

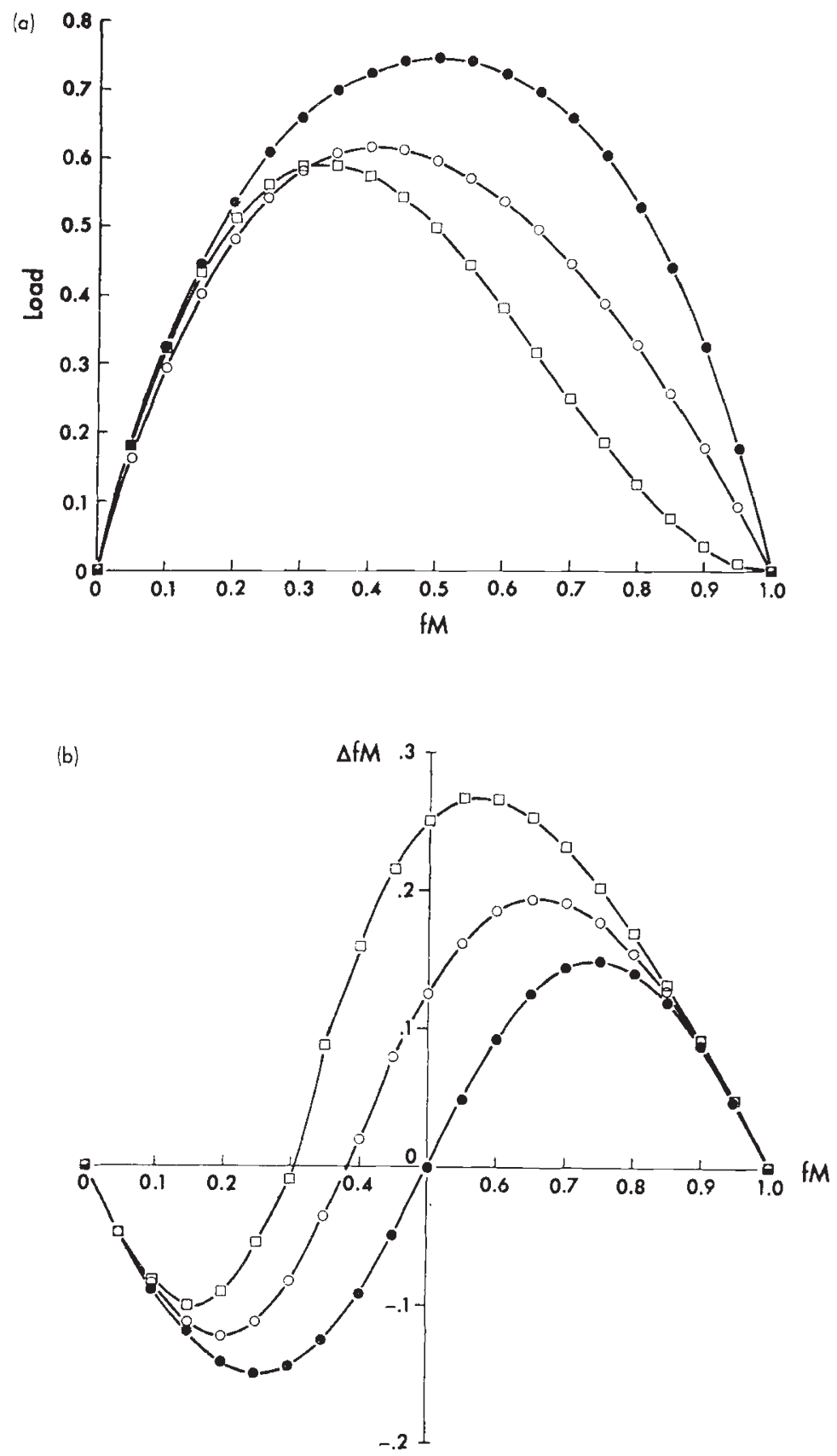

FIG. 7.-Effects of hybrid breakdown in a hybrid zone. (a) Genetic load at any given racial frequency in the zone. (b) The expected change in racial frequency at any given initial frequency after one generation of hybrid breakdown. The selection coefficients in the three regimes of hybrid breakdown are as follows:

$\begin{array}{llll} & s_{1} & s_{2} & s_{3} \\ 1 & 1 \cdot 0 & 1.0 & 1.0 \\ 2 & 1 \cdot 0 & 1.0 & 0 \\ 3 & 0.9 & 1.0 & 0.5\end{array}$


The results of 90 per cent breakdown in one of the backcrosses and 50 per cent breakdown in the other are in general intermediate between the two previously described examples (Fig. 7a and b, open circles). The equilibrium frequency and point of maximum genetic load occur at approximately $0 \cdot 4$. The frequencies on either side of the equilibrium point will again move towards one of the absorbing frequency boundaries at 0 or 1.0 . In each of the latter two examples, there will be an apparent deficit of hybrids because of the inclusion of the surviving backcross progeny in the parental classes. However, this effect is reduced in relation to the severity of the backcross breakdown.

Theoretical models of narrow clines have demonstrated that asymmetrical gene flow will move the cline without appreciably affecting its other characteristics such as width (Endler, 1977). Asymmetrical hybrid breakdown will also cause the position of a narrow cline to move because of the far greater survival on the side of the cline which suffers least from hybrid breakdown. However, in this case, the cline will move in the opposite direction to the direction of gene flow or introgression. If the model can be validly applied to the hybrid zone in Caledia, it would mean that the "Moreton" race has advanced, and may still be advancing, on the "Torresian" race, acquiring "Torresian" chromosomes during the movement of the hybrid zone. The movement of the hybrid zone will continue until an environmentally determined geographical equilibrium position is established (Key, 1968, 1974). At this point, there will be an increase in the fitness of the "Torresian" race, relative to the introgressed "Moreton" race, to counterbalance the effect of the asymmetrical breakdown. However, in the absence of an environmentally determined fitness gradient, the hybrid zone will continue to move unimpeded.

Although migration of the parental racial types is necessary for the maintenance of a hybrid zone, it has not been considered specifically in this model. However, if a zone of overlap is formed and there is no subsequent migration, the less frequent "foreign" racial type will become extinct on both sides of the zone, except at the equilibrium point, where there will be extinction of both racial types. Both the differences in population density on either side of the zone and the fact that the double extinction point is not at a frequency of 0.5 , explains the tendency for the position of the hybrid zone to move under a regime of asymmetrical hybrid breakdown. The rate of migration and tendency for dispersal are not known for these races of Caledia. Therefore the relationship between migration and rate of dispersal cannot be considered in detail. However, the extreme narrowness of the contact zone with the bulk of the transition occurring in a $200-\mathrm{m}$ interval, makes it likely that hybrid breakdown is severe and that migration occurs at a low rate for distances of approximately $1 \mathrm{k}$.

Severe F2 breakdown has already been demonstrated in laboratory hybridisation of the "Moreton" and "Torresian" races. Further, the asymmetry in the pattern of chromosmal disequilibria in the contact zone populations provides evidence for the differential effect of hybrid breakdown on the two races. The model of hybrid breakdown may have many applications in the study of narrow contact zones since it can explain both the presence of a stable narrow zone and also selective introgression.

Acknowledgments.--This work was carried out as part of a $\mathrm{Ph} . \mathrm{D}$. project under the supervision of Dr D. D. Shaw while the author was the recipient of a Commonwealth 
Postgraduate Research Award with A.N.U. supplementation. Dr Godfrey Hewitt provided constructive criticism of the manuscript, Dr D. D. Shaw, P. Wilkinson, R. Craft and V. Partridge provided assistance during the intensive sampling of the hybrid zone.

\section{REFERENCES}

BaIley, N. T. J. 1959. Statistical Methods in Biology. English Universities Press, London. BIGELOW, R. s. 1965. Hybrid zones and reproductive isolation. Evolution, 19, 449-458.

CRADDOCK, Е. M. 1971. Cytological studies of Australian Phasmatodea. Ph.D. thesis, University of Sydney, Australia.

GRADDOCK, E. M. 1975. Intraspecific karyotypic differentiation in the Australian Phasmatid Didymuria violescens (Leach). 1. The chromosome races and their structural and evolutionary relationships. Chromosoma (Berl.), 53, 1-24.

Endler, J. A. 1977. Geographic Variation, Clines and Speciation. Monogr. Pop. Biol., Princeton Univ.

HEwIT, G. M. 1975. A sex chromosome hybrid zone in the grasshopper Podisma pedestris (Orthoptera : Acrididae). Heredity, 35, 375-387.

Kеу, K. H. L. 1968. The concept of stasipatric speciation. Syst. Zool., 17, 14-22.

KEY, K. H. L. 1974. Speciation in the Australian Morabine grasshoppers. In Genetic Mechanisms of Speciation in Insects, ed. M. J. D. White, pp. 43-56. Australia and New Zealand Book Co.

LEWONTIN, R. C., AND FELSENSTEIn, J. 1965. The robustness of homogeneity tests in $2 \times \mathrm{N}$ tables. Biometrics, 21, 19-33.

MAYr, E. 1963. Animal Species and Evolution. Belknap Press, Harvard.

MORAN, c. 1978. Population studies of Caledia captiva (Orthoptera : Acridinae) in south east Queensland, Ph.D. thesis, A.N.U., Canberra.

MORAN, C., AND SHAW, D. D. 1977. Population cytogenetics of the genus Caledia (Orthoptera: Acridinae). III. Chromosomal polymorphism, racial parapatry and introgression. Chromosoma (Berl.), 63, 181-204.

Mrongovius, M. J. 1975. Studies of hybrids between members of viatica group of Morabine grasshoppers. Ph.D. thesis, University of Melbourne, Melbourne.

NAGLE, J. J., AND METTLER, L. E. 1969. Relative fitness of introgressed and parental populations of Drosophila mojavensis and D. arizonensis. Evolution, 23, 519-524.

NEVO, E., AND BAR-EL, H. 1976. Hybridization and speciation in fossorial mole rats. Evolution, 30, 831-840.

SHAW, D. D. 1976. Population cytogenetics of the genus Caledia (Orthoptera : Acridinae). I. Inter and intraspecific karyotype diversity. Chromosoma (Berl.), 54, 221-243.

SHoRT, L. L. 1972. Hybridization, taxonomy and avian evolution. Ann. Mo. Bot. Gard., $59,447-453$.

WHITE, M. J. D., BLACKITH, R. E., BLACKiTH, R. M., AND CHENEX, J. 1967. Cytogenetics of the viatica group of Morabine grasshoppers. I. The " coastal " species. Aust. F. Zool., 15, 263-302.

WHITE, M. J. D., KEY, K. H. L., ANDRÉ, M., AND CHENEY, J. 1969. Cytogenetics of the viatica group of Morabine grasshoppers. II. Kangaroo island populations. Aust. 7. Zool., $17,313-328$. 